\title{
Impact Mechanism and Effect of Financial Development on Industrial Agglomeration in China
}

\author{
Xiaowei Yang ${ }^{1}$ and Jianjun $\mathrm{Xu}^{2}$ \\ ${ }^{1}$ Business School, Ningbo City College of Vocational Technology, Ningbo, 315000, PR. China \\ ${ }^{2}$ Institute of Science and Technology Ningbo University, Ningbo, 315211, PR. China
}

\begin{abstract}
Based on the perspective of financial function, this paper firstly analyzes the promoting mechanism of financial development on industrial agglomeration, and then takes manufacturing industry for example and constructs the crossprovinces panel data model to analyze the effects of financial development on industrial agglomeration from the financial scale, financial structure and financial efficiency respectively. Theoretical analysis of this article shows that financial development mainly through the mechanism of capital formation, capital-oriented and entrepreneurs formed to promote the development of industrial agglomeration in a country or region. Empirical analysis results show that both the financial scale and financial efficiency remarkably promote the different provinces of the spatial concentration of manufacturing industry, but the financial structure doesn't adapt to the agglomeration of manufacturing industry. In addition, the results also show that the factors, such as export trade, economic basement, the size of the labor force, urbanization and level of service, play a key role in the development of manufacturing industry in China.
\end{abstract}

Keywords-financial development;industrial agglomeration; impact mechanism; panel data model

\section{INTRODUCTION}

Industrial agglomeration refers to the same type of industry or related industries concentrated and aggregated in a particular area. In today's globalized economy, industry aggregation is one of the most significant features of the world's economic activity. The process of industrial agglomeration affected by many factors. Marshall (1890)[1] from the economic externalities, Weber (1909)[2] from the transport costs, Krugnan(1991) [3]from the point of view of economies of scale, etctheoretically explained forming reasons of Industrial agglomeration.. Many Western scholars have the empirical tests on the basis of the above theoretical explication Max Keilbach(2007)[4] built spatial econometric model with the data of German federal state to confirm the existence of spatial spillover effects of human capital; Using data coming from 341 regions in France, Combes and Lafourcade(2002)[5] studied road transport costs for regional industry agglomeration effects; Paluzie (2001)[6] studied of industry panel data of 50 provinces in Spain, and found that economies of scale is the most important factor for industrial agglomeration. In addition, more and more scholars from the views of market integration, market potential and other aspects had been expanded and supplemented for industrial agglomeration(Aiginger and Pfaffermayr, 2004[7]; Hanson, 2005)[8]. Qian Shuitu and Jiang Le (2009) [9] used a panel model with data taking from 11 cities of Zhejiang Province in
China from 2000 to 2007 to analyze the impact of the financial structure of the industry agglomeration. The results showed that the loan structure had a significant positive role in promoting the performance of the industrial agglomeration, while the financing structure had no significant negative effect on industrial agglomeration; Ma Runping(2012)[10] constructed the panel data, including 13 citiesof Jiangsu province in China from 2000 to 2010 and analyzed the impact of the financial structure on the industrial agglomeration. The results showed the structure of indirect financing and securities financing both significantly promoted the industrial agglomeration in Jiangsu province, but the insurance industry didn'tpromote industrial agglomeration of Jiangsu province; Combined with 20 provinces in China from 1991-2007, Zhang Xiaodi and Wang Yongqi(2010)[11] analyzed the relationship between The entrepreneurship and industrial agglomeration. The results showed that the higher the efficiency of financial markets, the density of entrepreneurs is relatively high, and the scale and industrial agglomeration effect were relatively obvious; Guo Bingnan and Duan Fang (2011)[12] selected of 31 provinces from1999-2009 and builta dynamic panel data model to analyze the effectsof different endowments on China's industrial agglomeration. The results showed that the financial elements of the eastern and central areas have a significant role in promoting of industry concentration, while the promoting effect of financial elements on the Western industrial agglomeration is not significant.

Although the above literature data used different methods to confirm the influence of financial factors on industrial agglomeration, but few literature profiled the mechanism of financial development promoting industrial agglomeration, while the relevant empirical studies nor depth analyze the effects of size, structure and efficiency of financial development on industrial agglomeration. Different from the previous studies, in accordance with the general idea of combining theoretical and empirical analysis, the paper firstly discusses the mechanisms of financial development promoting industrial agglomeration from the perspective of financial functions, and then build cross-provincial panel to analyze the effect of financial size, financial structure and financial efficiency to industry agglomeration. This will help us have a more comprehensive understanding of the role of financial support in the process of industrial agglomeration. 


\section{The IMPACt MeChanism of FinANCIAL DEVELOPMENT ON INDUSTRIAL AGGLOMERATION}

Finance is the core of the modern economy. The performance of financial development reflects the expansion of the financial scale, optimization to the financial structure and improvement of financial efficiency. Financial system mainly through the allocation of resources, facilitation of risk diversification, promoting corporate governance, mobilization savings and facilitation the exchange of goods and services and other aspects of the function profound impact on many aspects of a country or region's economic development(Levine,1997)[13]. Industrial agglomeration a special phenomenon of industrial and economic development and industrial cluster development needs financial support. Financial development is not only the dynamic condition and important force to promote industrial agglomeration but also the starters and the nerve center of industrial agglomeration. To sum up, financial development mainly through the mechanism of capital formation, capital-oriented and entrepreneur formation to promote industry cluster development of a country or regions. As shown in figure1.

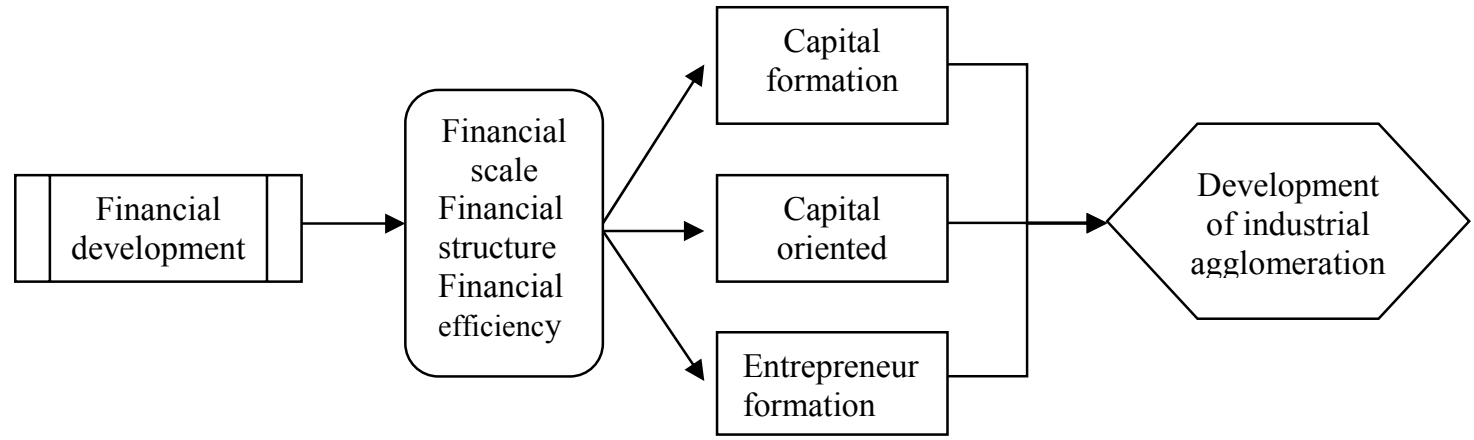

FIGURE I. THE IMPACT MECHANISM OF FINANCIAL DEVELOPMENT ON INDUSTRIAL AGGLOMERATION

\section{THE EFFECT OF FINANCIAL DEVELOPMENT ON INDUSTRY AGGLOMERATION:TAKING CHINA'S MANUFACTURING INDUSTRY FOR EXAMPLE}

\section{A. Econometric Models, Variables and Data}

For an in-depth analysis of the effect of China's financial development on industrial agglomeration, following Qian Shuitu and Jiang Le (2009)[9], we take manufacturing cluster indicators(LQ) as explanatory variables, financial development indicators (fin(j)) as the main explanatory variable and 5 important factors in affecting the manufacturing industry clusters as control variables $(\mathrm{CV})$ to construct thefollowing econometric model to analyze the effect of financial development on manufacturing industry agglomeration.

$$
\ln L Q_{i t}=\alpha_{0}+\beta_{i} \operatorname{lnfin}(j)_{i t}+\gamma_{i} \sum_{i=i}^{n} \ln C V_{i t}+\varepsilon_{i t}
$$

In which, control variables include export trade, economic infrastructure, workforce size, urbanization and service conditions. Constructional method of each indicator is described below:

We use the location quotient (LQ) indicators to measure the degree of concentration of manufacturing industry. Variable LQit indicates No.i unit as the manufacturing industry concentration degree in the $t$ period. The following is the calculation formula:

$$
\mathrm{LQ}_{\mathrm{it}}=\left[\left(\mathrm{E}_{\mathrm{i}} / \mathrm{E}_{\mathrm{i}}\right) /\left(\mathrm{E}_{\mathrm{s}} / \mathrm{E}_{\mathrm{k}}\right)\right]_{\mathrm{t}}
$$

Among them, the Eijis the $\mathrm{j}$-thmanufacturing industries in iprovince; Eiis the total industrial output of all manufacturing industries in the i-thprovince $\mathrm{I}$; Ekj is the $\mathrm{j}$-thindustrial production for the k-thnationwide manufacturing sector. Ekis the gross output value of industrial enterprises in nationwide $\mathrm{k}$. The location entropy of manufacturing industry includes 20 manufacturing industries, such as food processing, beverage manufacturing, general machinery manufacturing, et al.

We can investigate the level of financial development in a country or region (fin(j)) from the views of the financial scale, financial structure and financial efficiency. Following to Ran Guanghe et al(2011)[14], We build the indicators of financial development scale (finsize) in different provinces. the indicators of the financial development scale equals the amount of bank intermediary institutions' credit and financial markets directly funding divided by second industry of nominal gross domestic production(GDP); Financial structure indicators (finstru) equals the amount of bank intermediary credit divided by the total financing amount from bank intermediary credit and financial markets funding. The financial efficiency indicator (fineffi)equals loans divided by saving coming from the financial intermediaries, which also reflect the conversion capabilities of the savings-investment. Export trade (export) indicated by a degree of dependence on exports, that is the exports/GDP; economic foundation(avggdp) approximate equals per capita GDP, calculated from GDP divided by the total population; labor force (labor) represented by the total labor force at the end of the year; the process of urbanization (citiliza) represented by the urbanization rate, 
divided by urban and rural population; service level (service) expressed in relative size in services industry, which equals the output value of the tertiary industry divided by GDP of the province.

The sample of this study consists of 31 provincial-level administrative units in mainland China, the time span from 2000 to 2011, the underlying data taking from the China Industrial Economic Yearbook, the Statistical Yearbook of China, the China Finance Yearbook, the China Population Statistical Yearbook, the Yearbook of China's Regional Economic Statistics and Wind.

\section{B. Quantitative Analysis Results and Interpretation}

Based on model (1), under the condition of mixed effects, cross-section of fixed effects(FE) and section with random effects(RE), we use panel EGLS cross-sectional weighting method to estimate the impact of financial scale, financial structure and financial efficiency on industry agglomeration, the results are shown in Table 1.From Table 1, we know that the estimated parameters of the financial scale (lnfinsize)in $M(1)-M(3)$ is positive, and the significance of the t test about the estimated parameters of $\mathrm{M}(1)$ and $\mathrm{M}(2)$ are at $1 \%$ level, it suggests that scale financial significantly contributes to the spatial agglomeration of manufacturing industry. Similarly, from the estimation results of $M(4)$ and $M(5)$, we know that financial structure (lnfinstru) is significantly negative with the manufacturing cluster, which indicate that the amount of direct financing in the stock market and banking intermediation loan financing cannot adapt to the cluster development of manufacturing industry. The estimated coefficients of financial efficiency (lnfineffi) in $\mathrm{M}(7)-\mathrm{M}(9)$ is positive, and the significance of $t$ test about the parameters in $\mathrm{M}(7)$ atthe $5 \%$ level, which, to some extent, help explain the implication of the financial efficiency improvement on the cluster development of manufacturing industry in China.

TABLE I. THE IMPACT OF FINANCIAL DEVELOPMENT ON MANUFACTURING INDUSTRY AGGLOMERATION IN WHOLE

\begin{tabular}{|c|c|c|c|c|c|c|c|c|c|}
\hline & \multicolumn{3}{|c|}{ Financial size } & \multicolumn{3}{|c|}{ Financial structure } & \multicolumn{3}{|c|}{ Financial efficient } \\
\hline & $\mathrm{M}(1)$ & M (2) & M (3) & M (4) & $\mathrm{M}(5)$ & $\mathrm{M}(6)$ & $\mathrm{M}(7)$ & M (8) & $\mathrm{M}(9)$ \\
\hline \multirow{2}{*}{ lnfinsize } & $0.090^{*}$ & $0.051^{*}$ & 0.018 & & & & & & \\
\hline & 5.966 & 3.234 & 0.827 & & & & & & \\
\hline \multirow{2}{*}{ lnfinstru } & & & & $-0.019^{*}$ & $-0.004^{* * *}$ & -0.003 & & & \\
\hline & & & & -5.544 & -1.829 & -1.045 & & & \\
\hline \multirow{2}{*}{ lnfineffi } & & & & & & & $0.035^{* *}$ & 0.014 & 0.009 \\
\hline & & & & & & & 2.106 & 1.491 & 0.558 \\
\hline \multirow{2}{*}{ lnexport } & $0.020^{*}$ & $0.015^{*}$ & $0.018^{*}$ & $0.031^{*}$ & $0.018^{*}$ & $0.020^{*}$ & $0.023^{*}$ & $0.016^{*}$ & $0.018^{*}$ \\
\hline & 4.065 & 4.379 & 3.9 & 6.159 & 5.087 & 4.209 & 4.888 & 4.771 & 3.981 \\
\hline \multirow{2}{*}{ lnavggdp } & $0.049^{*}$ & $0.045^{*}$ & $0.033^{*}$ & $0.052^{*}$ & $0.034^{*}$ & $0.032^{*}$ & $0.049^{*}$ & $0.034^{*}$ & $0.032^{*}$ \\
\hline & 5.202 & 4.059 & 3.008 & 5.678 & 3.395 & 3.023 & 5.36 & 3.381 & 2.967 \\
\hline \multirow{2}{*}{ Inlabor } & $0.079^{*}$ & 0.05 & $0.064^{*}$ & $0.061^{*}$ & $0.089^{* *}$ & $0.064^{*}$ & $0.063^{*}$ & $0.088^{* *}$ & $0.061^{* *}$ \\
\hline & 12.919 & 0.986 & 2.677 & 10.187 & 1.917 & 2.819 & 11.699 & 1.871 & 2.482 \\
\hline \multirow{2}{*}{ Incitiliza } & $0.049^{* *}$ & 0.008 & $0.031^{* * *}$ & $0.053^{*}$ & 0.003 & $0.031^{* * *}$ & $0.058^{*}$ & 0.005 & $0.031^{* * *}$ \\
\hline & 2.785 & 0.631 & 1.783 & 3.016 & 0.289 & 1.776 & 3.266 & 0.397 & 1.747 \\
\hline \multirow{2}{*}{ lnservice } & $0.030^{* * *}$ & $0.057^{*}$ & $0.061^{*}$ & $0.078^{*}$ & $0.056^{*}$ & $0.066^{*}$ & $0.063^{*}$ & $0.055^{*}$ & $0.064^{*}$ \\
\hline & 1.788 & 3.851 & 3.653 & 5.457 & 4.085 & 4.024 & 4.506 & 4.003 & 3.947 \\
\hline \multirow{2}{*}{$\mathrm{C}$} & $-0.497^{*}$ & -0.292 & $-0.330^{* *}$ & $-0.310^{*}$ & -0.551 & $-0.324^{* *}$ & $-0.245^{*}$ & -0.527 & -0.294 \\
\hline & -8.784 & -0.781 & -1.81 & -6.711 & -1.59 & -1.878 & -6.083 & -1.499 & -1.564 \\
\hline R-sq & 0.399 & 0.799 & 0.083 & 0.354 & 0.794 & 0.087 & 0.352 & 0.793 & 0.079 \\
\hline Adj.R-sq & 0.389 & 0.778 & 0.068 & 0.343 & 0.772 & 0.072 & 0.341 & 0.771 & 0.064 \\
\hline F-stat. & 40.348 & 37.093 & 5.537 & 33.045 & 35.799 & 5.742 & 33.037 & 35.652 & 5.213 \\
\hline Effect & POLS & $\mathrm{FE}$ & $\mathrm{RE}$ & POLS & $\mathrm{FE}$ & RE & POLS & FE & $\mathrm{RE}$ \\
\hline Obs. & 372 & 372 & 372 & 372 & 372 & 372 & 372 & 372 & 372 \\
\hline
\end{tabular}

Further analysis of the estimated coefficients of the different control variables of the model, you can also get some important conclusions. The estimated parameter of export trade indicators(lnexport) in $\mathrm{M}(1)-\mathrm{M}(9)$ are significantly positive, indicating that the expansion of the export trade is in favor of spatial agglomeration of China's manufacturing industry. Meanwhile, we also find that the economic foundation, labor force, the processes of urbanization and service levels are positively correlated with the spatial agglomeration of manufacturing industry, this means that further promoting economic development, the expansion of the labor force, rapid urbanization and raising the level of 
service, particularly raising producer services levels would facilitate the agglomeration development of Chinese manufacturing industry.

\section{CONCLUSIONS}

Based on the perspective of financial function, The paper firstly discusses the mechanisms of financial development promoting industrial agglomeration from the perspective of financial functions, and then build cross-provincial panel to analyze the effect of financial size, financial structure and financial efficiency to industry agglomeration and their regional differences. Theoretical analysis of this article shows that financial development mainly through the mechanism of capital formation, capital-oriented and entrepreneurs formed to promote the development of industrial agglomeration in a country or region. Empirical analysis shows that financial scale and financial efficiency have a significant contribution to the agglomeration development of the manufacturing industry, while financial structures is not conducive to the spatial agglomeration of China's manufacturing industry. In addition, we also find that the factor such as export trade, economic infrastructure, labor force, the processes of urbanization and service level and so on have experienced a significant role in the spatial agglomeration of China's manufacturing industry.

The above conclusions on depends on the corresponding financial policy tools to promote the role of enlightenment in China industry cluster development has very important:

(1) overall, the financial policy adjustment should not only continue to expand the scale and improve financial efficiency financial, but also focuses on the adjustment and optimization of the financial structure of the existing, to further improve the direct financing in the financing activities in the proportion of. Specifically, is to establish a perfect classification of multi level capital market system, the full range, including compliance with industrial agglomeration development demand of main board market, second board market, the third board market, property rights trading market and technology property right transaction market; is vigorously developing the risk investment institutions to provide equity financing, as the birth agglomeration region of small and medium-sized enterprises; is to vigorously develop small and medium-sized financial institutions, health support and guide the development of folk finance, as the enterprises in the cluster to solve the financing needs to open up new financing channels.

(2) promoting the strong support of industry of modern financial system requires not only the development of agglomeration, but also to promote the common through export promotion, promotion and service follow up means city. Specifically, is to actively develop the export trade, expand trade with neighboring countries to promote the development of industrial agglomeration; is to accelerate the pace of urbanization, based on the conditions of small towns to bring good and in the process of rural urbanization, reform of the household registration system and other means to promote the development of industrial agglomeration; is to vigorously develop the productive service industry, including to improve the education and training of the quality and skills of workers and reduce the traffic transport and storage industry production and circulation cost, to promote the development of industrial agglomeration.

\section{ACKNOWLEDGEMENT}

This article is financed by the Ministry of Education of Humanities and Social Sciences Research Youth Fund Project (No. 17YJCZH218; No. 16YJCZH124) and Major Projects on Humanities and Social Sciences of Colleges and Universities in Zhejiang Province (No. 2016QN005)

\section{REFERENCES}

[1] Marshal. Principles of Economies[M].London: Macmillan Press, 1890.

[2] Weber, A. Theory of Location of Industries[M].Chicago: University of Chicago Press, 1909.

[3] Krugman P. Geography and Trade[M].Massachusetts: The MIT Press, 1991.

[4] Max Keilbach. Marshallian Externalities and the dynamics of agglomeration and regional growth[R].Centre for European Economic ResearchWorking Paper,2007.

[5] Combes P. \& Lafourcade M. Transport costs decline and regional inequalities: evidence from france[R]. CEPR Discussion Paper No. 2894,2001.

[6] Paluzie E.,Pons J.\&Tirado,D. Regional integration and specialization patterns in Spain[J].Regional Studies, 35 (4), pp.285-296,2001.

[7] Aiginger K \&Pfaffermayr M.The single market and geographic concentration in Europe [J]. Review of International Economics, 12 (1), pp.1-11,2004.

[8] Hanson,G.H. Market potential, increasing returns, and geographic concentration[J].Journal of International Economics, 2005(67), pp.1-24.

[9] Qian Shuitu \&Jiang Le. The impact of Zhejiang regional financial structure on industrial cluster-an empirical analysis based on panel data [J]. Statistical Research, (10), pp.62-67, 2009.

[10] Ma Runping. Financial development and industrial cluster: a panel data analysis based on Jiangsu province [J]. Social Sciences in Ningxia, (5), pp.38-43, 2012.

[11] Zhang Xiaodi\&Wang Yongqi. Entrepreneur and industrial agglomeration: coupling effectsof the financial markets[J]. China's Industrial Economy, (5), pp.59-67, 2010.

[12] Guo Bingnan\&Duan Fang. International fragmentation of production, factor endowments and industrial agglomeration-based on the GMM test of provincial dynamic panel model [J]. Journal of Shanxi Finance and Economics University, (4), pp.34-43, 2011.

[13] Levine. R. Financial development and economic growth: views and agenda [J].Journal of Economic Literature, (35), pp. 688-726,1997.

[14] Ran Guanghe, Wu Hao\&Shao Tengwei. Financial support for development of industrial clusters: three Western provinces (municipalities) of the empirical evidence[J]. Social Sciences in Guangdong, (3), pp.34-41, 2011. 